\title{
NOTAS
}

\section{Juristas para la justicia}

\section{Fernando Santos Urbaneja'}

Resumen: La crisis económica ha hecho visibles situaciones de grave injusticia y ha generadora su vez, otras muchas por el modo en que se ha abordado su solución. Parecería que correspondía a los juristas alzar su voz contar este estado de cosas, pero salvo muy raras excepciones no lo han hecho. Lo cierto es que tanto jueces, como fiscales y abogados, tienen en sus manos instrumentos para procurar la "justicia". También el mundo de la universidad debería implicarse en esta empresa. En el fondo late la concepción que cada profesional tenga de su labor. El trabajo confronta a los juristas de la tribu A con los de la tribu B. más allá del ámbito de los profesionales de la Justicia, los tiempos demandan la generación de un vigoroso movimiento ciudad no que recupere el espíritu de la Constitución de 1978, al tiempo que avance hacia un "nuevo constitucionalismo" capaz de hacer frente a los poderosos "lobbies" que se han colocado por encima de gobiernos e instituciones.

Palabras clave: Crisis económica, justicia, nuevo constitucionalismo, profesionales de la justicia.

Fecha de recepción: 28 de octubre de 2013.

Fecha de admisión definitiva: 16 de septiembre de 2015.

\section{Lawyers for Justice}

Abstract: The economic crisis has made visible situations of grave injustice and is generating the same time, many others by the way they have addressed their solution.

\section{Juristes pour la justice}

Résumé: La crise économique a rendu visibles situations $d^{\prime}$ injustice grave et a générateur de tourner, beaucoup d'autres dans la façon dont votre solution a traité.

' Fiscal de la Audiencia Provincial de Córdoba. Coordinador del Foro Andaluz del Bienestar Mental. 
It would seem that corresponded to the lawyers speak out have this state of affairs, but with few exceptions they have not done. The truth is that methane judges, prosecutors and lawyers as have instruments in their hands to seek "justice". Also the world of the university should be involved in this venture. At heart beats conception that every professional has its work. The work confronts the jurists of the tribe with the tribe B. beyond the scope of legal practitioners, the times demand the creation of a vigorous movement that city did not recover the spirit of the 1978 Constitution, the while moving towards a "new constitutionalism" able to cope with the powerful "lobbies" that have been placed above governments and institutions.

Key-words: Economic crisis, justice, new constitutionalism, legal professionals.
Il semblerait que vous correspondaient aux avocats élever la voix en disant cet état de choses, mais sauf très rares exceptions n'ont pas encore fait. En effet, juges, procureurs et avocats, de disposer d'instruments dans leurs mains à la «justice». Aussi le monde de l'Université devrait être associé dans cette entreprise. Dans l'arrière-plan bat la conception que chaque professionnel a dans son travail. Le travail confronte les avocats d'une tribu avec la tribu de B. au-delà de la portée des professionnels de la justice, temps exigent la génération d'une vigoureux mouvement ville pas récupérer l'esprit de la Constitution de 1978, au moment où allervers un «nouveau constitutionnalisme» capable de faire face aux puissants "lobbies » qui ont été placés au-dessus des gouvernements et des institutions.

Mots clé: Crise économique, justice, nouveau constitutionnalisme, practiciens du droit.

\section{Planteamiento}

Al publicar estas líneas se cumplen siete años de la quiebra de "Lehman Brothers" (15 de septiembre de 2008), acontecimiento señalado como desencadenante de la gravísima crisis económica que seguimos padeciendo. Durante estos años la injusticia ha crecido de modo exponencial.

La crisis no la están pagando los que la provocaron, sino una masa ingente de ciudadanos que han visto reducida su renta y sus derechos sociales, haciéndoles más pobres y más vulnerables. Todo este inmenso volumen de renta hurtado a los ciudadanos, está siendo transferido al delirante sistema financiero que se había montado, (basado en la especulación sin límites), con la vana intención de sanearlo pues, se comporta como un agujero negro que engulle todo lo que se le echa.

No es que antes del año 2008 no hubiese injusticia y abusos. Los había, pero resultaban menos visibles. En los largos años de bonanza, cuando los ciudadanos pensaban en las próximas vacaciones o en la adquisición del último modelo de 
automóvil, el discurso de la "injusticia" resultaba difícil de arraigar. Muchos decían, "Si bueno, pero mientras estemos bien...

Actualmente los ciudadanos de la, en otros tiempos "distraída Europa", saben que los gobernantes que han elegido mandan realmente muy poco y que están a merced de fuerzas amorales e insaciables que no tienen rostro, solo una irrefrenable ansia de riquezas y de poder. Este hecho notorio ha propiciado la aparición de movimientos sociales de denuncia y de protesta con proposición de modelos alternativos que puedan agruparse bajo la rúbrica "Otro mundo es posible".

Todo esto es sobradamente conocido por lo que no insistiré en ello. Lo que yo quiero denunciar es un gran silencio, "el silencio de los juristas", lo cual resulta especialmente llamativo cuando la principal víctima de todo este proceso ha sido la Justicia.

Por lo tanto, no quiero hacer ni me corresponde, un discurso desde la óptica de los movimientos sociales que se manifiestan jIndignados!, ni desde la perspectiva de los sindicatos, ONG, partidos políticos, etc..., sino de la perspectiva de un jurista.

\section{La perspectiva jurídica}

Descartados ya otros ámbitos, es obvio que la perspectiva jurídica no es uniforme, sino plural. La interpretación de las leyes ofrece, legítimamente, soluciones dispares. Por otro lado, el jurista, como ciudadano, puede tener su opinión sobre la oportunidad o no de una determinada legislación.

En mi caso, dada mi condición de fiscal, me es exigible un juicio ponderado. Adelanto ya que no soy un abolicionista. Asumo gustosamente el sistema y legalidad vigente derivado de la Constitución de 1978, que es un prodigio de equilibrio entre distintas fuerzas e intereses.

\section{La Constitución de 1978}

Cabe señalar lo siguiente:

1.- La Constitución reconoce en su art. 38 la libertad de empresa y de mercado pero tal libertad debe ser compatible con el derecho a la salud de los ciudadanos 
(art. 43), con la salvaguarda de los derechos de los consumidores (art. 51), el respeto al medio ambiente (art. 45), el derecho a una vivienda digna (art. 47) y la vida familiar (art. 39), sabiendo, además, que toda la riqueza del país debe estar orientada al bien común (art. 128).

Este equilibrio ideal es seguro que no llegó a darse nunca en plenitud pero, en algún momento, parecía que nos acercábamos.

Al desatarse la crisis se multiplicaron los abusos. Los ciudadanos pensaron que sus gobiernos les defenderían, frenarían las propuestas de reducción de sus derechos, de sus salarios, de progresivo desmantelamiento de un Estado de bienestar cuya consecución había costado dos guerras mundiales. Pero no fue así, los gobiernos se aliaron con "los mercados", asumieron sus directrices y se pusieron a su disposición bajo la justificación pretendida, machaconamente repetida de que "no hay otra solución", "no se puede hacer otra cosa". La mera amenaza de "la intervención" doblegó a gobiernos y parlamentos. Muchos ciudadanos seguían esta deriva con estupor.

El punto más álgido de este proceso se produjo con la reforma de la Constitución, gestada en el mes de agosto de 2011, que dio lugar a la reforma de su art. 135 con fecha 27 de septiembre de 2011.

Resulta difícil conciliar la lectura de los arts. 128 y el reformado art. 135 de la Constitución. Representan opciones contrarias.

El art. 128, que supone el cierre de bóveda del sistema económico de la Constitución dice que "toda la riqueza del país, en sus distintas formas y sea cual fuere su titularidad, está subordinada al interés general".

El art. 135 allana el camino para la subordinación de toda la riqueza del país al preferente interés de unos pocos, precisamente de aquéllos que estuvieron en la génesis del problema. No cabe mayor injusticia.

Este sometimiento hace que los valores superiores de nuestro ordenamiento jurídico, proclamados por la Constitución en su art. 1 (libertad, justicia, igualdad y pluralismo político) se resquebrajen y diluyan, arrastrando a su paso lo que constituye el faro, la esencia y la piedra angular de aquélla, expuesto y proclamado en su art. 10-1:

"La dignidad de la persona, los derechos inviolables que le son inherentes, el libre desarrollo de la personalidad, el respeto a la ley y a los derechos de los demás, son el fundamento del orden y de la paz social." 
Sobre el marco legal expuesto y pasando de lo difuso a lo concreto para centrar la cuestión, tengo que decir que:

- No todo el mercado financiero es injusto.

- No todas las entidades financieras han tenido la misma conducta.

- No todas han reaccionado igual ante las consecuencias de la crisis.

Mis críticas mayores no van dirigidas a los dirigentes de los sistemas financieros amorales e insaciables que hicieron de la especulación delirante su seña de identidad, sino a los gobernantes que lo propiciaron desmontando los órganos de control o haciéndolos permanecer pasivos cuando la deriva de las cosas era conocida y aún cabía poner algún remedio.

En este sentido, la carta dirigida con fecha 26 de mayo de 2006 por la Asociación de Inspectores del Banco de España a Pedro Solbes, en ese momento Vicepresidente segundo del Gobierno y ministro de Economía y Hacienda, es bien elocuente respecto de lo que quiero decir.

Mis críticas mayores se centran en este ámbito porque los mercados financieros no son "función pública", mientras que nuestros gobernantes sí. Lo cierto es que todo este conjunto de cosas han producido una enorme infelicidad social. Suelo decir que a nuestra Constitución le faltó formular explícitamente el derecho más importante o quizás, el más explicativo, cual es el "derecho a tener la oportunidad de ser feliz". El concatenado de decisiones claramente favorecedoras de los intereses del sistema financiero está causando sufrimiento en una parte muy amplia de la población y dificultando mucho la consecución de este derecho que, aunque no expresamente formulado, es profundamente anhelado por todas las personas sin excepción.

\section{La Administración de justicia}

Frente a este estado de cosas, ¿qué papel le corresponde jugar a la Administración de justicia? Es importante, en primer lugar, reflexionar sobre el nombre: administración de justicia. Bello nombre, pero equívoco. La justicia no acude a los tribunales lo mismo que la salud no acude a los hospitales. La justicia vive fuera, en todos los compromisos que se cumplen, en todas las normas que se respetan, tanto mejor si se aceptan con convencimiento de su bondad. 
Lo que a los tribunales compete es la administración de reparación de la injusticia. Es más, solo les compete la reparación de una parte de las injusticias, las que se comenten "contra la ley", pues existen injusticias legales que los jueces y tribunales tienen que soportar si bien, como más adelante señalaré, no tienen por qué hacerlo acríticamente.

La reparación de la injusticia es tarea ingrata pues, en primer lugar, no siempre es posible y, cuando es factible suele ser parcial y tardía. Entre la reparación de la injusticia que anhela el ofendido ("justicia del corazón") y la que los tribunales están en condiciones de dar, puede mediar un abismo. La reparación que anhela el ofendido es "emocional ", "pronta" y "completa", mientras que la reparación de los tribunales, en el mejor de los casos, se producirá, como ya se ha señalado en fecha muy alejada del agravio. El abogado debe ser el intérprete que traduzca y haga caer en la cuenta al cliente de esta dolorosa realidad, para que tome sus decisiones con "conocimiento de causa".

¿Qué hacer frente a las leyes injustas? La gente común queda perpleja cuando se le coloca frente a esta realidad y preguntan ¿ Cómo es posible que existan leyes injustas en los países democráticos? ¿Cómo ha podido ocurrir esto? Por el juego de las relaciones de poder.

En la edad media el "mercado" era una institución perfectamente definida y controlada. La posibilidad de celebrar "mercado" era una concesión que el rey hacía a una localidad a la que quería premiar o favorecer por los servicios prestados. En el año 1944 el científico social y economista húngaro Karl Polanyi en su obra titulada La gran transformación, advertía de modo profético que "el mercado" estaba empezando a desbordar su espacio tradicional y comenzaba a colocarse por encima de las familias y después lo haría sobre los mismos Estados, hasta llegar a convertirse en un tirano global, sin escrúpulos.

Esta profecía comenzó a hacerse realidad en la década de los años 70 del pasado siglo. Desde entonces los mercados dictan las normas por lo que puede decirse que desde ese momento es el mercado el que quita y pone al rey.

El ciudadano ha visto cómo la soberanía del Estado era entregada a estos despiadados actores guiados únicamente por un ansia de lucro desenfrenado. Estos poderosos "lobbies" han influido en los gobernantes y han logrado que se legisle a su favor, a favor de unos pocos, dando lugar a legislaciones claramente injustas. En suma, no es a los jueces a quienes corresponde derogar las leyes injustas, sino a los parlamentarios, a los representantes de la soberanía nacional y a los gobiernos dentro de sus respectivas competencias. 
¿Lo están haciendo? En mi opinión, de modo muy tímido. Cuando la crisis golpeó a la sociedad española (especialmente a algunos de sus sectores) y se hizo visible la tremenda injusticia que este hecho representaba, surgió en la opinión pública un indignado grito pidiendo "justicia" y algunos brotes de rebelión. El Gobierno se vio atrapado entre dos tensiones:

- De un lado, lo que le pedían los "lobbies".

- De otro, lo que le pedían los indignados ciudadanos.

El Gobierno ha optado por la siguiente estrategia: promulgar una multitud de decretos-leyes que se anunciaba vendrían a paliar los problemas y a mejorar la situación de los más desfavorecidos pero que, cuando se leían con detenimiento, se comprobaba que contenían reformas o medidas "nada inquietantes" para los intereses de los grandes "lobbies". Se ha producido un hecho llamativo en torno al tema de los "desahucios". El Gobierno central promulgó un decreto con medidas muy tímidas. Por su parte, el gobierno andaluz promovió otro decreto con medidas un poco más audaces (expropiación temporal a los Bancos de la facultad de uso de viviendas procedentes de adjudicación por impago de hipotecas). Este decreto fue recurrido ante el Tribunal constitucional por el Gobierno central. El Gobierno de Andalucía respondió (25-IX-2013) aprobando una "Ley antidesahucios" de mayor calado y contenido que el anterior decreto. Es previsible que el Gobierno central la impugne también ante el Tribunal constitucional quizás porque tanto el Fondo Monetario Internacional como algunos organismos comunitarios habían mostrado su inquietud por la medida.

Pero dejemos a parlamentarios y gobernantes enfrascados en sus contiendas y pasemos a preguntarnos ¿qué pueden hacer los juristas? (jueces, fiscales, abogados, profesores universitarios).

Antes de responder a esta pregunta hay que caer en la cuenta de algo que, quizás por ser evidente, pasa inadvertido. Entre los juristas pueden distinguirse dos grandes tribus que, en términos simples y extremos podemos describir como:

Tribu A (en decrecimiento). A la que pertenecen:

* Los que se hacen preguntas sobre la justicia de las leyes.

* Los que hacen labor de interpretación de las normas.

* Los que comparan éstas con la Constitución y el Derecho comunitario.

* Los que tienen presentes los ideales de la Justicia.

*A los que les importa el sufrimiento de los justiciables. 
Tribu B (en crecimiento). A la que pertenecen:

* Los que no se hacen preguntas sobre la justicia de las leyes.

* Los que no hacen labor de interpretación de las normas.

* Los que no comparan éstas con la Constitución y el Derecho comunitario.

* Los que no tienen presentes los ideales de la Justicia.

* A los que no les importa el sufrimiento de los justiciables.

Hasta aquí no hay ningún problema. Yo me siento mucho más identificado con la Tribu A que con la Tribu B pero ésta me parece una opción legítima que yo respeto. En cambio, tengo la impresión de que a los que nos adscribimos a la cada vez más reducida Tribu A, se nos quiere negar la condición de "juristas", algunos nos la niegan sin contemplaciones diciendo que hacemos "filosofía", "literatura" - vendemos "moralina detestable". Y yo pregunto: ¿invocar la Constitución es filosofía? ¿2Reivindicar la Justicia es inapropiado? ¿ ¿Denunciar el abuso del Derecho es impertinente?

Lo curioso y, por otro lado, totalmente lógico es comprobar que el ciudadano medio, el ciudadano de la calle sí nos entiende y nos reconoce como "juristas".

Estoy preocupado por esta deriva. Voy a relatar a continuación tres hechos o sucesos que me dieron mucho que pensar:

\section{Hecho 1}

En el año 2004 estuve en Uruguay. El viaje, entre otras actividades, conllevaba el impartir conferencias en distintas universidades. En una de ellas hablé, como siempre, de la Constitución española de 1978. Al terminar el catedrático que me había presentado y que se disponía a moderar el coloquio manifestó: "El fiscal español nos acaba de recordar que nosotros también tenemos una constitución". ¡Me quedé perplejo! Me preguntaba: ¿̇cómo es posible que pueda ocurrir esto? ¿Cómo es posible que se pueda olvidar que se tiene una constitución? ¿Qué pasó? Es como si el mejor cuadro que presidió durante años el salón de la casa, un día (o una noche) alguien lo subió al trastero y allí cayó en el olvido.

\section{Hecho 2}

En el año 2011 estuve en Argentina. Mi cometido era apoyar la recién aprobada Ley de Salud Mental frente al intenso debate generado por este acontecimiento. A mi me tocaba combatir las objeciones "jurídicas" realizadas por un influyente sector 
de la universidad, capitaneado por un venerable catedrático de Derecho civil. Programaron nuestra intervención conjunta en un congreso de amplia convocatoria y unas horas antes nos buscamos y tuvimos ocasión de hablar. Conocía las objeciones realizadas a la Ley por este apreciado catedrático pues las había publicado. Eran exactas, verdaderas, precisas y coherentes, si bien ninguna afectaba a la esencia de la Ley, sino a aspectos meramente formales de coordinación con la legislación de algunos estados federales. Después de saludarnos cortésmente le dije a quien debía ser mi contrincante: "Conozco sus objeciones a la ley, estoy de acuerdo con ellas pero jesta ley no le parece justa?" El viejo y sabio catedrático quedó confundido, casi aturdido, se repuso un poco, meditó sobre la pregunta y respondió. Sí, me parece justa. Entonces le dije, tenemos que apoyarla. Y para mi sorpresa, el docto catedrático, formado en las más rigurosas esencias del positivismo jurídico, en la intervención conjunta de la tarde suavizó enormemente sus objeciones y casi pareció que defendía la ley para estupor de un grupo de profesores que ocupaban la primera fila del enorme salón de actos y para mi regocijo.

El Hecho 1 y el Hecho 2 tienen algo en común jel asombro! La mención de la Constitución produjo asombro. La apelación a la Justicia produjo perplejidad y reflexión. ¿ Nos puede estar pasando a nosotros algo similar? Creo que si. El convencimiento me vino con el siguiente hecho.

\section{Hecho 3}

Después de 20 años dando clase en la Escuela de Práctica Jurídica de Córdoba a sucesivas promociones de licenciados en Derecho que querían encaminar sus pasos por el ejercicio de la abogacía, estaba empezando a notar que aquella pasión por los ideales de justicia que empapaban a las primeras promociones con quien me encontré, empezaban a decaer.

Un día hice en clase la siguiente pregunta: ¿esta ley os parece justa? Y un alumno respondió con toda naturalidad: ¿qué más da? Es legal. No critico en absoluto la respuesta ni mucho menos al alumno. Me parece una respuesta aceptable pero, desde luego, no es mi respuesta. No es de mi Tribu. Durante los 20 años que impartí clases en la citada Escuela siempre dije a mis alumnos que yo no podría haber ejercido un solo minuto mi profesión de fiscal si no existiese el art. 3 del Código civil, el que establece los criterios "legales" de interpretación de las leyes y que dispone:

Las normas se interpretarán según el sentido propio de sus palabras, en relación con el contexto, los antecedentes históricos y legislativos y la realidad social del tiempo en que han de ser aplicadas, atendiendo fundamentalmente al espíritu y finalidad de aquellas. 
El estudio del contexto legislativo con sus normas sobre preferencia de aplicación de las normas, el conocimiento de los precedentes históricos, el análisis sociológico y la atención a los principios y fundamentos del Derecho, es ineludible para la labor del jurista. No basta leer los artículos.

Pues bien todo este discurso (histórico, sociológico, filosófico), no es "metajurídico", sino netamente jurídico y los que lo cultivan no son "metajuristas", sino juristas verdaderos, pues sin estos criterios el jurista queda ciego, manco y mudo algo, por otra parte, muy atractivo para determinados sectores.

Aún, si como algunos sostienen y practican, hay que atenerse a la "letra de la ley", hay que decir que la letra de la ley contiene estos conceptos que dan "luz" al Derecho.

Así, el art. 1 de la Constitución proclama:

España se constituye en un Estado social y democrático de Derecho, que propugna como valores superiores de su ordenamiento jurídico la libertad, la justicia, la igualdad y el pluralismo político.

\section{El Art 3 -2 del Código civil}

La equidad habrá de ponderarse en la aplicación de las normas, si bien las resoluciones de los Tribunales sólo podrán descansar de manera exclusiva en ella cuando la ley expresamente lo permita.

\section{El art. 7 del Código civil}

1. Los derechos deberán ejercitarse conforme a las exigencias de la buena fe.

2. La ley no ampara el abuso del derecho o el ejercicio antisocial del mismo.

A estos preceptos hay que añadir el art. 5 de la Ley Orgánica del Poder Judicial, el art. 247 de la Ley de Enjuiciamiento Civil, etc...

Está claro que los textos legales fundamentales contienen alusiones "literales" a la justicia, la equidad, la buena fe, así como la preeminencia y prevalencia de éstos sobre la legislación de rango menor, en caso de contradicción de ésta con aquélla.

Ocurre que los "lobbies" rara vez inciden en la legislación de mayor rango (excepción hecha de la reforma del art. 135 de la Constitución) pues ello resultaría demasiado llamativo. Gustan, en cambio, conseguir de las autoridades y gobernantes, decretos, órdenes ministeriales, incluso meras circulares, escritas bajo su dictado muy favorecedoras de sus intereses. Si alguno de los perjudicados (caso 
infrecuente) es capaz de acudir a los tribunales demandando tutela, lo normal es que los jueces, una vez que se exhibe e invoca esta legislación menor, la apliquen sin contemplaciones cuando, si elevasen los ojos hacia la legislación fundamental, advertirían que es contraria a ésta. Conocida es la frase atribuida al conde de Romanones: "Haced vosotros las leyes y dejadme a mi los reglamentos".

Los "lobbies" no quieren que el juez levante los ojos y mire por encima de la legislación que se le presenta. Inmediatamente tachan esta conducta de "arbitraria". Sin embargo no solo no lo es, sino que nuestro ordenamiento jurídico no contempla al juez como alguien que tiene que aceptar acríticamente la legislación que se le invoca, sino que tiene el deber de comprobar su vigencia y su sumisión a la Constitución y a los textos de Derecho comunitario de mayor rango. En caso de contradicción, el ordenamiento ofrece al juez mecanismos de corrección. Esto nos lleva a plantearnos las siguientes preguntas:

\section{¿Qué pueden, deben o pueden hacer los jueces?}

El art. 117 de la Constitución proclama que:

La justicia emana del pueblo y se administra en nombre del Rey por Jueces y Magistrados integrantes del poder judicial, independientes, inamovibles, responsables y sometidos únicamente al imperio de la Ley.

El ejercicio de la potestad jurisdiccional en todo tipo de procesos, juzgando y haciendo ejecutar lo juzgado, corresponde exclusivamente a los Juzgados y Tribunales determinados por las Leyes, según las normas de competencia y procedimiento que las mismas establezcan.

\section{A.- Deben aplicar la ley, lo cual exige interpretarla}

La interpretación no es una "facultad", es una "obligación". La interpretación de las leyes debe hacerse conforme a los ya examinados criterios legales recogidos en el art. 3 del Código civil.

\section{B.- Pueden cuestionar la adecuación de la ley a la Constitución o al Derecho comunitario}

El juez español no tiene la obligación de acatar ciegamente la ley, puede cuestionarla, cuando considera que es contraria a la Constitución o al Derecho comunitario esencial contenido en los tratados. 
No son escasos los jueces que plantean "cuestiones de inconstitucionalidad" para su decisión por el Tribunal constitucional y algunos se han atrevido a plantear "peticiones de decisión prejudicial" ante el Tribunal de Justicia de la Unión Europea. Así lo hizo, por ejemplo, el titular del Juzgado de lo Mercantil n ${ }^{\circ} 3$ de Barcelona, lo que dio lugar al pronunciamiento de fecha 14 de marzo de 2013 del aludido tribunal, que declara la inadecuación de la legislación española en materia de ejecución hipotecaria a la legislación comunitaria, en concreto a la Directiva 93/13/CEE del Consejo, obligando al gobierno a tomar la iniciativa que conduciría a la "Ley 1/2013 de 14 de mayo, de medidas para reforzar la protección a los deudores hipotecarios, reestructuración de deuda y alquiler social". Cosa distinta es si tal ley ha venido a corregir suficientemente la falta denunciada falta de sintonía.

\section{¿Qué deben o pueden hacer los fiscales?}

El art. 124 de la Constitución proclama que:

El Ministerio Fiscal, sin perjuicio de las funciones encomendadas a otros órganos, tiene por misión promover la acción de la justicia en defensa de la legalidad, de los derechos de los ciudadanos y del interés público tutelado por la Ley, de oficio o a petición de los interesados, así como velar por la independencia de los Tribunales y procurar ante éstos la satisfacción del interés social.

\section{A.- Los fiscales deben velar por el cumplimiento de la legalidad}

Resulta llamativo que siendo el ministerio fiscal un cualificado defensor de la legalidad, no se conceda al fiscal general del Estado legitimación para interponer la cuestión de inconstitucionalidad.

El fiscal que actúa en el procedimiento, si bien no tiene legitimación para interponer cuestiones de inconstitucionalidad, sí puede proponer al juez que la plantee.

En los últimos lustros asistimos a debates sociales que enfrentan unos colectivos con otros y es frecuente que todos ellos quieran tener al ministerio fiscal de su parte para que combata, "sin muchos miramientos" al contrincante.

Mi opinión al respecto la manifesté en un artículo escrito en el mes de marzo de 2007, titulado "Reyes de bastos", que concluye del siguiente modo:

Es verdad que en los últimos años se advierte un modo de proceder que puede enunciarse del siguiente modo: detectado un problema social grave se reacciona lanzando una especie de "cruzadas" de las que sería ariete el Derecho Penal. 
Hay quien piensa que los Fiscales estaríamos llamados a ocupar el papel de "Reyes de Bastos" dispuestos a aporrear sin contemplaciones a cualquier miembro del colectivo "señalado".

No, esta no es nuestra labor. Nos prepararon para el "microanálisis", para escudriñar en lo profundo de las personas y de los hechos. A veces el análisis nos lleva a la culpa y otras a la disculpa.

\section{B.- Los fiscales pueden proponer reformas legislativas}

Resulta especialmente importante la posibilidad que los fiscales tienen de proponer reformas legislativas:

- En sentido positivo: porque estiman que hace falta promulgarlas.

- En sentido negativo: porque estiman que es preciso derogarlas por el perjuicio que causan a colectivos que se encuentran bajo su amparo.

Jueces y fiscales ejercen una función pública de ahí que estén especialmente obligados a un ejercicio leal con la Constitución, el resto de las leyes y la protección de los intereses legítimos de los ciudadanos bien promoviendo la acción de la justicia (Ministerio Fiscal), bien resolviendo motivadamente los conflictos y litigios ante ellos planteados (tribunales).

Varios son los males que pueden aquejar a los profesionales que ejercen estas funciones. Señalaré ahora los siguientes:

- La tendencia a rehuir los asuntos voluminosos o complejos

Sobre esta cuestión escribí en el mes de mayo de 2009 un artículo titulado: "De lo 'int' a lo 'sent', a propósito de lo judicial", donde profundizo en esta realidad. Diré como resumen que nuestros Juzgados no se encuentran en condiciones de tramitar determinados asuntos que, por su volumen, sobrepasan su capacidad de respuesta.

- La tendencia a rehuir los asuntos que afectan a los políticos

Jueces y fiscales se encuentran indefensos "de hecho" frente a las acometidas de grupos y organizaciones políticas cuyas actuaciones sobrepasan, en algunos casos, el ámbito de la crítica legítima. Esta denunciada indefensión gravita y pesa sobre jueces y fiscales a la hora de tomar sus decisiones. 
- La indiferencia sobre las consecuencias de nuestro trabajo

En este punto voy a transcribir un párrafo demoledor de Piero Calamandrei en su conocida obra El elogio de los jueces:

Bajo el puente de la justicia pasan todos los dolores, todas las miserias, todas la aberraciones, todas las opiniones políticas, todos los intereses sociales.

Sería de desear que el juez estuviera en condiciones de volver a vivir en sí mismo para comprenderlos, todos y cada uno de esos sentimientos; haber probado la extenuación de quien roba para satisfacer el hambre, o el tormento del que mata por celos; ser alternativamente (y a veces al mismo tiempo), inquilino y arrendador, aparcero y propietario de tierras, obrero huelguista y patrón industrial.

Justicia es comprensión, es decir, considerar a la vez y armonizarlos, los intereses opuestos: la sociedad de hoy y las esperanzas de mañana; las razones de quien defiende y las de quien acusa.

Pero, si el Juez comprendiera todo, posiblemente no podría ya juzgar. (Quien todo lo comprende, está dispuesto a perdonarlo todo).

Quizá, para que la justicia pueda alcanzar los limitados fines que nuestra sociedad le asigna, necesita, para funcionar, de horizontes no demasiados amplios y de cierto espíritu conservador que puede parecer mezquindad.

Los horizontes del juez están fijados por las leyes. Si el juez comprendiera lo que hay más allá, posiblemente no las podría aplicar con tranquilidad de conciencia.

Es conveniente que no se percate que la función que nuestra sociedad asigna a la Justicia es, a menudo, la de conservar las injusticias consagradas en los códigos.

\section{¿Qué pueden hacer los abogados?}

El Estatuto general de la abogacía (R.D. 658/2001 de 22 de junio) proclama en su art. 1-1:

La abogacía es una profesión libre e independiente que presta un servicio a la sociedad en interés público y que se ejerce en régimen de libre y leal competencia, por medio del consejo y la defensa de derechos e intereses públicos o privados, mediante la aplicación de la ciencia y la técnica jurídicas, en orden a la concordia, a la efectividad de los derechos y libertades fundamentales y a la Justicia.

La abogacía se ha transformado completamente en los últimos veinte años. Apenas queda ya nada del abogado con lustros de experiencia y despacho unipersonal con uno o dos pasantes. Esto ya es historia. Se hizo ineludible la especialización y la colaboración. Hasta aquí nada que objetar. 
La exacerbación de este fenómeno ha tenido dos consecuencias muy dañosas: el primer grito de alarma lo dio Alejandro Nieto en el año 2003 en un artículo publicado en la revista Lex Nova, titulado "La explotación del abogado por empresas de abogados" en el que describía y lamentaba la despiadada deriva de la profesión.

Mucho más recientemente (2012) Niall Ferguson, en su obra La gran degeneración: como decaen las instituciones y mueren las economías denuncia como una de las causas del declive actual de occidente, lo que denomina "El Imperio de los Abogados" que ha venido a sustituir al Imperio de la Ley, mediante la utilización de toda clase de artimañas contrarias a la Justicia y a la buena fe procesal.

Encontramos, entre los abogados, profesionales que se adscriben a la Tribu $A$ (en franco decrecimiento) y otros a la Tribu B (en franco crecimiento). Lo que resulta claro es que la apelación de los viejos maestros de deontología -"Si en el ejercicio profesional ves que la Ley se enfrenta a la Justicia. ¡Pelea por la Justicia!"-encuentra cada vez menos servidores.

En este punto, he recibido con extraordinaria satisfacción la noticia del nombramiento de Alberto Mata Rodríguez, Abogado de Gómez-Acebo \& Pombo, que ejerce en EE. UU., como "mejor letrado joven del año". Se trata de una convocatoria a nivel mundial. Lo relevante para mí es que el galardón se ha otorgado teniendo muy presente "su compromiso ético" y su altruista asistencia a grupos desfavorecidos.

\section{¿Qué puede hacer la universidad?}

En la universidad se forman los juristas y de ahí se nutrirán las numerosas profesiones jurídicas. El Derecho pretende encarnar la Justicia por lo que la reflexión sobre este valor debería ser algo natural en las aulas. Me dicen que no es así, salvo raras excepciones. Tras la crisis y una vez constatado que la especulación sin límites y la más absoluta falta de ética de los actores financieros ha estado en la base de la misma, algunas prestigiosas "Escuelas de negocios" han "improvisado" una asignatura de "Etica" en el programa de los costosísimos cursos que ofrecen. Demasiado tarde. Esto hay que aprenderlo mucho antes. 


\section{Epílogo}

En definitiva:

1. Urge articular un movimiento de "juristas para la Justicia" que reivindique y practique este ideal en los términos plasmados en la Constitución de 1978.

2. Urge recuperar los valores de la Constitución de 1978 en su conjunto.

3. Creo que, a la vez, es preciso plantear las bases de un "nuevo constitucionalismo" que responda a la realidad actual y sus riesgos. El constitucionalismo clásico contempló el binomio "ciudadano-Estado" otorgando armas al primero para defenderse de los posibles abusos del segundo. Ahora este esquema no sirve en la medida que por encima del Estado se han colocado fuerzas a las que no elegimos pero toman las decisiones en su exclusivo interés. Frente a esta nueva forma de dominación deben articularse medios de defensa que irían desde la desobediencia civil al aumento de los controles democráticos de los partidos (primarias, listas abiertas, etc...).

4. Correlativo a la modificación de la "Constitución" ha de venir la modificación de la "anti-Constitución" esto es, del Código penal. En este punto las perspectivas no pueden ser más tristes pues el actual proyecto de reforma del Código penal en tramitación, más ahonda en la represión penal del desfavorecido, que en la tipificación de las conductas denominadas "de guante blanco" que tanto escandalizan al ciudadano medio. 